\title{
Forked fascio-cutaneous supraclavicular artery flap for burned shoulder
}

\author{
James Roy Kanjoor \\ Belhoul Specialty Hospital, Dubai, UAE
}

Address for correspondence: Dr. James Roy Kanjoor, Belhoul Specialty Hospital, POB 5527 Dubai, UAE, E-mail: roykanjoor@yahoo.com

\section{ABSTRACT}

Deep burns of the shoulder region quite often result in the exposure of the joint. Either a partially or completely exposed shoulder joint surrounded by burnt tissue presents difficulty for coverage by local tissues. A case of deep burn with partially exposed joint, where successful coverage was carried out by a local fascio-cutaneous supra clavicular artery forked flap is presented. The flap was based on two perforators from the peripheral distribution area of the supra-clavicular artery and proved to be a good flap in such circumstances

\section{KEY WORDS}

Burnt shoulder, forked flap, perforator

\section{INTRODUCTION}

solated deep burn of the shoulder region is a rare occurrence but if it occurs in association with exposure of the joint, it may present a problem for the coverage. The depth of the burn is directly proportional to temperature and time of exposure. Prolonged exposure to heat resulted in a deep burn even damaging a part of the muscles covering the shoulder joint in this patient. The exposed joint capsule and biceps tendon surrounded by friable granulation tissue and eschar presented a problem for coverage using local tissues. Transposing two small flaps to cover this large defect was possible based on the perforators of the Supraclavicular artery.

\section{CASE HISTORY}

A 45-year-old male patient presented to the outpatient department with an isolated deep burn over the anterolateral and superior surface of the right shoulder of two weeks duration. The patient was a drug addict who sustained flame burns due to his clothes catching fire, which were left unextinguished for a while. He ignored the burn wound and did not seek medical advice. His relatives forcefully brought him to the outpatient clinic two weeks later. It was about a $1 \%$ TBSA full thickness burn partly covered with eschar and partly with granulation tissues [Figure 1]. The antero-lateral part of the joint capsule measuring about $5 \mathrm{~cm} \mathrm{x} 4 \mathrm{~cm}$ and part of the biceps tendon was exposed [Figure 1]. The shoulder movements were in full range and painless, but it produced bulging of the capsule in the wound though there was no leakage of synovial fluid.

The preoperative investigations were within normal limits. The wound swab showed no growth. Thrice daily dressing with tulle and saline gauze was carried out to prepare the wound for surgery. Psychiatrist consultation was sought to manage drug withdrawal symptoms and postoperative pain management. 
Pre-operative Doppler study revealed good signals over the supraclavicular artery territory, firstly at the level of the triangle between the medial part of the clavicle, Sternocleidomastoid muscle and external jugular vein and also over the medial part of the shoulder region [Figure 2]. The medial part of the shoulder had another signal most probably from the deltoid branch of the thoraco-acromial axis.

On the $17^{\text {th }}$ post burn day the patient was taken to the theatre and under general anesthesia, the burn wound was debrided. The capsule of the shoulder joint was exposed in the anterior aspect [Figure 3]. A forked flap with a superior arm of $12 \mathrm{~cm} \times 5 \mathrm{~cm}$ and an inferior arm of $8 \mathrm{~cm} \times 4 \mathrm{~cm}$ based on the perforators within the supraclavicular artery territory was designed. The dissection of the superior arm of the flap from the distal to the proximal oriented along the supra-scapular region,

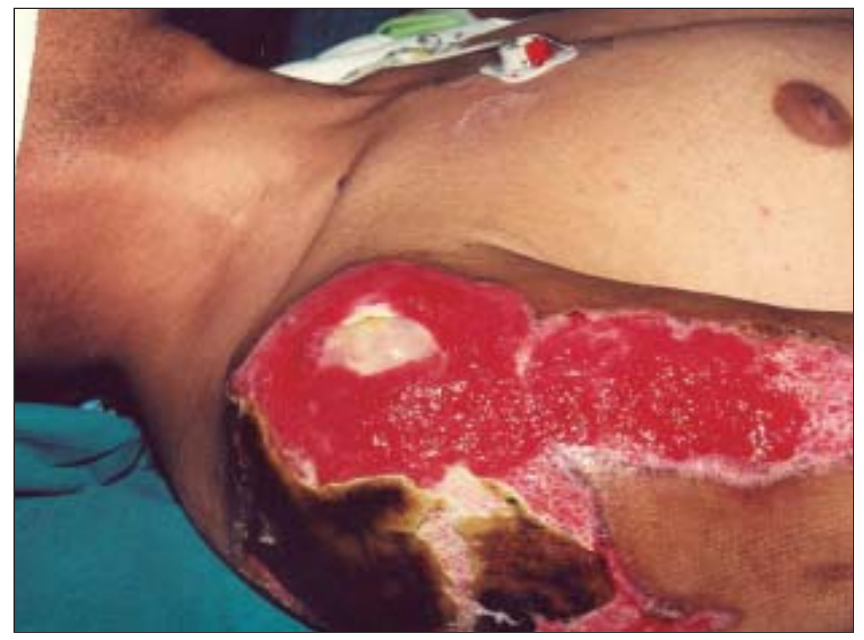

Figure 1: Deep burn right shoulder with exposed joint capsule and biceps tendon

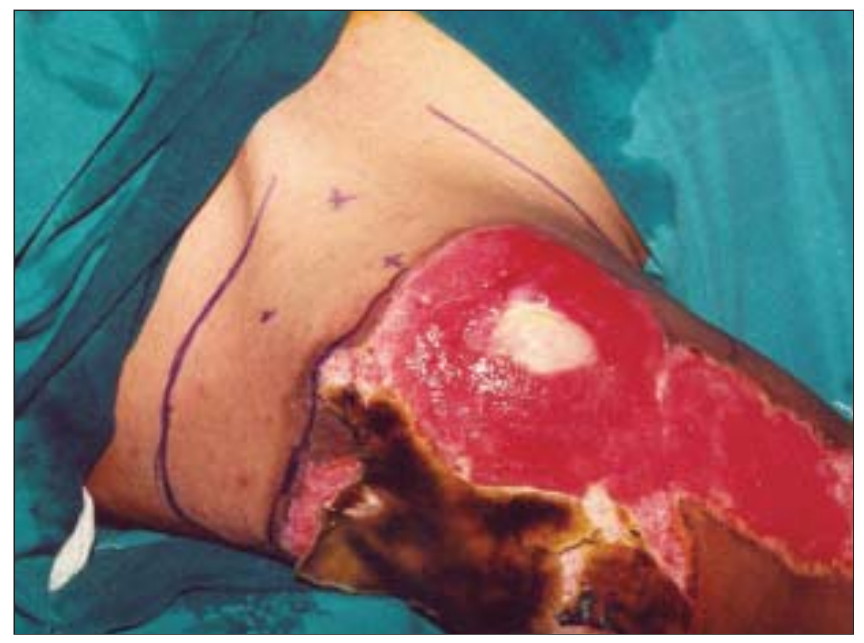

Figure 2: The base of the flap in the territory of the supraclavicular artery shown by Doppler study revealed a well-defined arterio-venous pedicle coursing the center of the flap corresponding the Doppler signal [Figure 3]. The inferior arm of the flap was marked along the medial aspect of the anterior shoulder region based on the perforators of the same vessels and possibly with an augmented supply from the deltoid branch of the thoraco-acromial axis [Figure 3]. The flaps were dissected from the distal to the proximal towards the base and found to be of adequate size to cover the desired area. Both flaps were sutured along the inner border and a few deep sutures were applied to fix the flaps [Figure 4]. The remaining raw areas along with the secondary defects were covered by split skin graft. His postoperative period was uneventful and the flaps survival and graft take was full, with primary wound healing [Figure 5]. The physiotherapy for the shoulder movements was started ten days postoperatively and he regained full range of

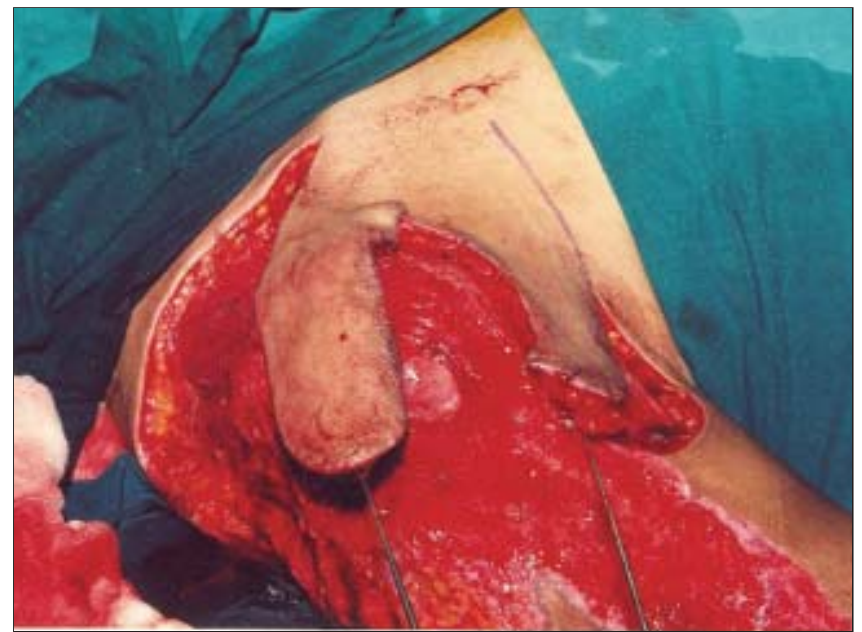

Figure 3: The burn area after debridement showing the exposed joint and tendon and two arms of the fork flap dissected

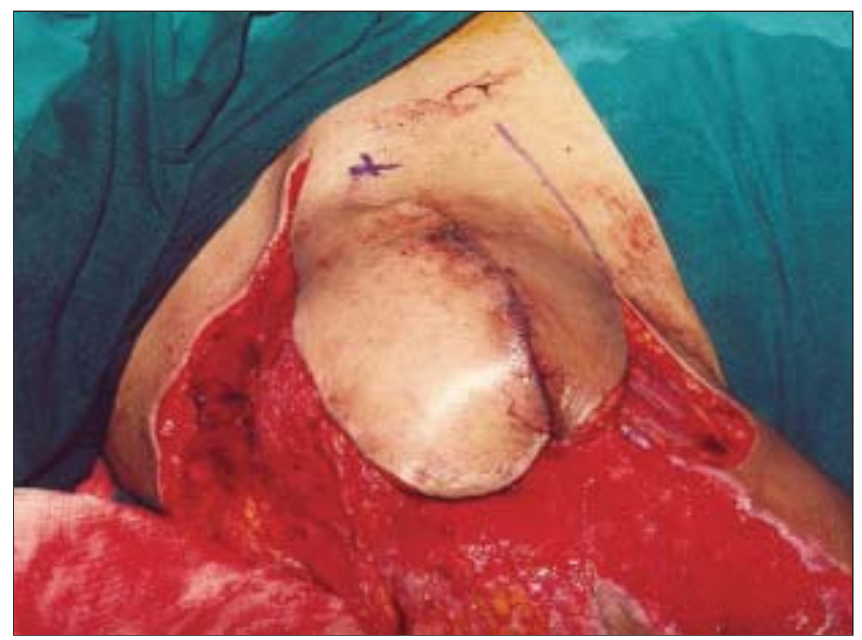

Figure 4: The two arms of the fork flap are sutured together to form a single flap 
movements in a short time [Figure 6]. He was discharged on the $12^{\text {th }}$ postoperative day and followed up for one month in the outpatient clinic, but was lost to further follow-up.

\section{DISCUSSION}

The options to cover a defect of this kind would have been to use either a distant flap or a free flap. The forked flap as described covered the exposed joint capsule and biceps tendon successfully and the remainder area was skin grafted including both secondary defects, which merged smoothly with the burnt area. The supraclavicular artery flap has been reported for head and neck reconstruction following tumor surgery or for the post burn contracture release, but the English literature review did not reveal use of it as reported here.

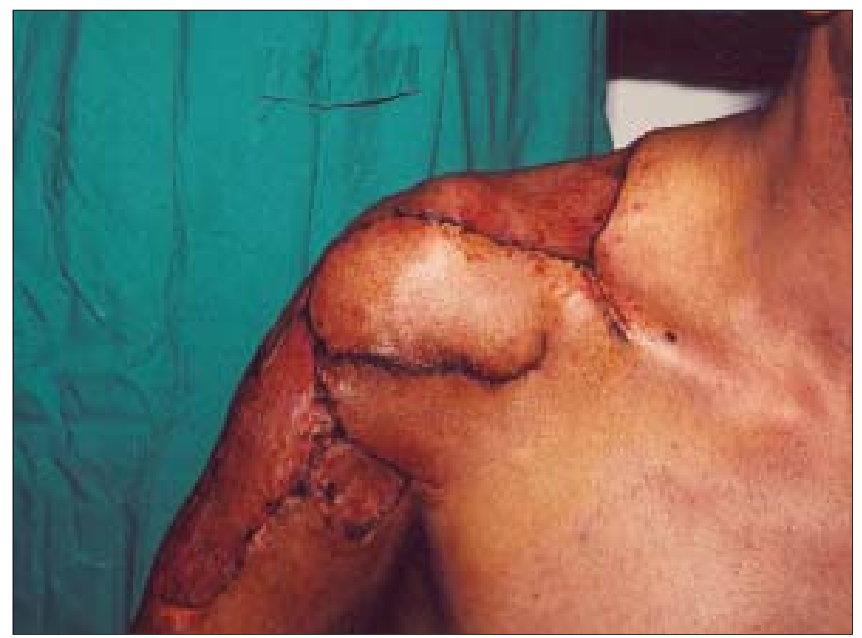

Figure 5: The exposed joint and tendon covered with flap and the remaining area skin grafted shown after healing

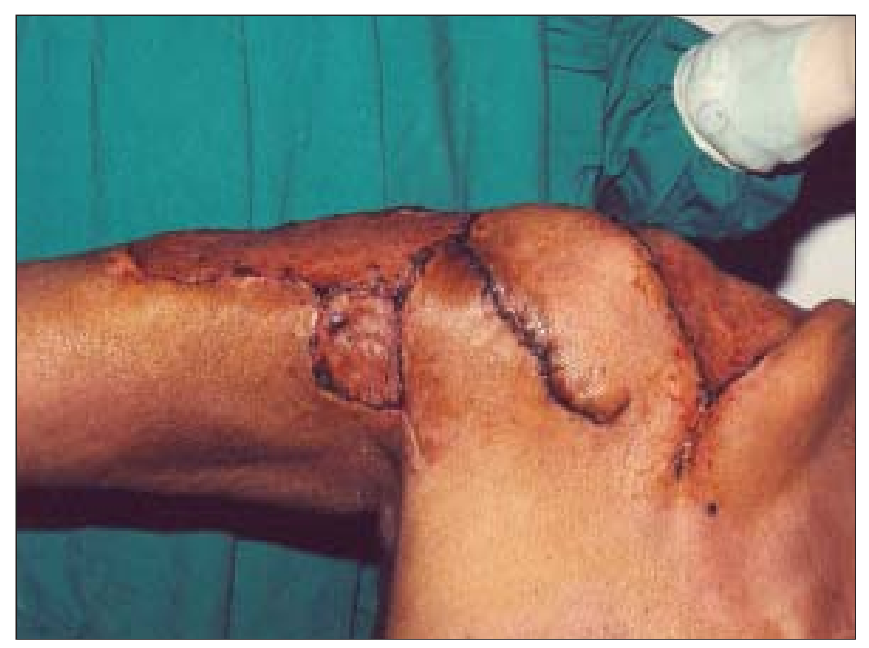

Figure 6: The shoulder movements regained within ten days after healing
In 1979, Lamberty ${ }^{1}$ was the first to describe the axial pattern of the shoulder flap based on the Supraclavicular artery. Pallua et $\mathrm{al}^{2}$ used this flap as an island flap for releasing post burn mentosternal contractures. They subsequently reported the vascular study on 19 cadaver dissections and dye injections. ${ }^{3}$ Their findings showed the territory of this flap in the neck and the shoulder.

The Supraclavicular artery arises from the transverse cervical artery (TCA) about $2-3 \mathrm{~cm}$ after the origin of TCA from the first part of the subclavian artery. ${ }^{4}$ Though Lamberty has given the name to this artery, up to now misconceptions about the terminology still exist, and the angiosomes have not been defined exactly. ${ }^{5}$ The boundaries of the flap fall within the skin territories of the Supraclavicular artery. The vascular territory extends from the Supraclavicular region to the shoulder cap. The distal part of the angiosome is on the ventral surface of the deltoid muscle. ${ }^{3}$ The perforator signal of the inferior horn was well within this territory. When the two flaps were sutured together, it appeared very much like the supraclavicular artery flap described by Pallua. ${ }^{3}$ The donor defects of both flaps merged smoothly with the skin grafted adjacent areas. There was no functional limitation of the shoulder movements. The choice of two smaller flaps instead of one large flap either from above or below the clavicle proved to be better in reducing the donor area morbidity.

To cover the shoulder a thin flap of good skin texture matching the adjacent area is preferred, in contrast to a bulky myocutaneous or free flap. Perforator-based flaps from the adjacent area are preferable. The flap is easy to execute, less time-consuming and may have some sensory input. The supraclavicular artery forked flap is a good alternative for burned shoulder coverage.

\section{REFERENCES}

1. Lamberty $\mathrm{BGH}$. The supra-clavicular axial patterned flap. $\mathrm{Br} \mathrm{J}$ Plast Surg 1979;32:207-12.

2. Pallua N, Machens HG, Rennekampff O, Becker M, Berger A. The fasciocutaneous supraclavicular artery island flap for releasing postburn mentosternal contractures. Plast Reconstr Surg 1997;99:1878-84.

3. Pallua N, Noah EM. The tunnelled supraclavicular island flap: An optimized technique for head and neck reconstruction. Plast Reconstr Surg 1999;105:842-51.

4. Cormack GC, Lamberty BGH. The arterial anatomy of skin flaps. Edinburgh: Churchil Livingstone; 1994.

5. Mizerny BR, Lessard ML, Black MJ. Transverse cervical artery fasciocutaneous free flap for head and neck reconstruction: Initial anatomic and dye studies. Otolaryngol Head Neck Surg 1995;113:564-8. 